\title{
Институциональные изменения системы высшего образования в Республике Бурятия
}

Ю.Г. БЮРАЕВА, доктор социологических наук, Отдел региональных экономических исследований Бурятского научного центра СО РАН, Улан-Удэ. E-mail: julbur@yandex.ru

В статье анализируется ряд современных тенденций в системе высшего образования Республики Бурятия. Автор акцентирует внимание на кризисных моментах, определяющих неготовность высшего образования, в периферийном регионе стать основой формирования экономики знаний ввиду снижения качества подготовки, а также качественного и количественного несоответствия выпускаемых специалистов реальным потребностям экономики региона. Подчеркивается необходимость поиска собственных путей развития высшего образования в регионе посредством предоставления уникальных возможностей для обучающихся. Основные выводы базируются на данных социологических исследований автора по проблемам качества образования и рынка труда Республики Бурятия.

Ключевые слова: высшее образование, Республика Бурятия, регион, реформирование образования, качество образования

\section{Постановка проблемы}

С начала рыночных преобразований в России система высшего образования претерпевает перманентное реформирование. Новый виток ее модернизации связан с позиционированием современного этапа развития экономики и общества как инновационного [Харченко, Бусыгин, 2007]. Следовательно, возрастает роль высшего образования как источника соответствующих высококвалифицированных кадров. Однако современное состояние его системы, тем более в периферийных регионах, пока не позволяет рассматривать его в качестве основы формирования в России экономики знаний, что обусловлено рядом накопившихся противоречий.

В этой связи исследовательский фокус автора направлен на то, как институциональные преобразования системы высшего образования проявляются в Республике Бурятия, что можно сделать для решения наиболее важных проблем. Эмпирической базой 
для исследования послужили данные Бурятстата ${ }^{1}$; результаты социологических опросов образовательных стратегий учеников 11 класса ${ }^{2}$ и студентов выпускных курсов вузов Республики Бурятия ${ }^{3}$.

Следует отметить, что все страны в той или иной степени переживают кризис образования, теоретическое осмысление которого было начато в Европе после выхода монографии Ф. Кумбса [Кумбс, 1970]. Главная проблема состоит в том, что система образования не успевает адаптироваться к меняющимся условиям жизни и социальным вызовам, появлению новых приоритетов в обществе, его информатизации.

Многие отечественные исследователи также указывают на наличие кризиса и необходимость трансформация высшего образования, поскольку существующие его модели уже неэффективны [Аникина и др., 2016; Арсентьева, Харченко, 2015]. Однако если за рубежом кризис обусловлен главным образом быстрыми темпами научно-технического процесса и усложнением условий жизни, то в России - в первую очередь сменой социально-политического уклада и деиндустриализацией.

\section{Массовизация высшего образования}

С началом реформ произошло обесценивание человеческого капитала, накопленного в советскую эпоху, вследствие сокращения производственной сферы и появления новых видов экономической деятельности, что потребовало новых знаний и умений.

Участники рынка труда во избежание потенциальной безработицы начали предпринимать активные меры, направленные на решение данной проблемы. Этот процесс был обозначен Р. Капелюшниковым как превращение всей страны в первой половине 1990-х годов в один огромный учебный класс. В условиях быстрых изменений на рынке труда высшее образование позволяет легче переходить с одного рабочего места на другое.

\footnotetext{
${ }^{1}$ Социальная сфера [Эл. ресурс]. URL: http://burstat.gks.ru/wps/wcm/connect/rosstat_ts/ burstat/ru/statistics/sphere/ (дата обращения: 27.04.2018).

${ }^{2}$ Пилотное исследование проведено автором в 2015 г. на основе анкетного опроса. Опрошено 200 учеников 11-го класса Республики Бурятия на основе многоступенчатой стратифицированной выборки.

${ }^{3}$ Исследование по оценке качества образования проведено автором в 2018 г. Объект исследования - студенты выпускных курсов очного отделения вузов Республики Бурятия. Опрошено 800 выпускников на основе целенаправленной выборки. Метод отбора - «сплошной массив» (опрашивались все присутствующие на занятиях студенты).
} 
Кроме того, уровень образования стал влиять на размер доходов и возможность карьерного роста. В переходный период отдача от образования достигла 7-8\% [Капелюшников, 2005], хотя еще в конце 1980-х гг. вузовский диплом практически не давал никаких преференций и не влиял на величину заработков. Система образования отреагировала на стремительно растущий спрос массовизацией высшего образования, что присуще многим странам мира [Фрумин, Карной, 2014]. Также к числу причин стремительного развития высшего образования в РФ можно отнести предоставление отсрочки от призыва в армию студентам с весны 1989 г.

В Республике Бурятия перекос подготовки кадров в пользу высшего образования привел к ускоренному росту численности студентов вузов и количества специалистов с высшим образованием. За двадцатилетний период численность приема на обучение в вузах увеличилась в 2,8 раза, студентов - в 2,3, выпускников - в 3,9 (рис. 1). Темп роста выпуска кадров республиканскими вузами даже превысил среднероссийский показатель (в 3,6 раза). Пик пришелся на 2010 г.

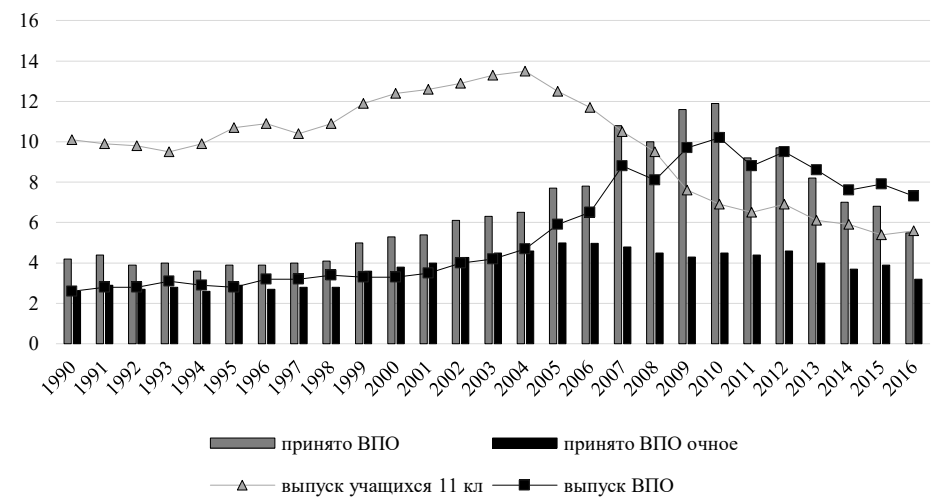

Pис. 1. Динамика соотношения выпуска учащихся 11-го класса, приема и выпуска в вузы Республики Бурятия, 1990-2016 гг., тыс. чел.

Основной контингент получающих профессиональное образование в республике - это студенты вузов. Их доля составляет $53 \%$, по программам подготовки специалистов среднего звена 
обучаются $36 \%$, квалифицированных рабочих, служащих - всего $11 \%$, получающих специальность.

Сегодня Бурятия занимает 26-е место в РФ по количеству студентов бакалавриата, специалитета и магистратуры на 10 тыс. населения. В Сибирском федеральном округе - 5-е место после Томской, Омской, Новосибирской и Иркутской областей, что является достаточно высоким показателем, учитывая, что количество вузов в республике значительно меньше, чем у соседей (например, в четыре раза меньше, чем в Новосибирской области).

\section{Вузы республики}

В регионе функционируют четыре государственных вуза Бурятский государственный университет (БГУ), Бурятская государственная сельскохозяйственная академия (БГСХА), Восточно-Сибирский государственный университет технологий и управления (ВСГУТУ), Восточно-Сибирский государственный институт культуры и искусств (ВСГИК) и один негосударственный вуз - Байкальский экономико-правовой институт (БЭПИ). Кроме них на коммерческой основе работают девять филиалов иногородних вузов, обучение в которых ведется преимущественно в заочной форме. Исключение составляют филиалы ИрГУПС и СибГУТИ, в которых предусмотрено небольшое количество бюджетных мест.

Каждый из государственных вузов республики имеет свою специализацию и ведомственную принадлежность. БГУ создан как классический университет в 1995 г. на базе педагогического института и филиала НГУ в г. Улан-Удэ. Обучение ведется по 71 программе бакалавриата, специалитета и магистратуры ${ }^{4}$. ВСГУТУ организован в 1962 г. с целью подготовки инженеров для бурно развивающихся в то время отраслей промышленности Сибири и Дальнего Востока. Здесь реализуется 89 программ бакалавриата, специалитета и магистратуры․ ВСГИК с 1960 г. ведет подготовку кадров для сферы культуры и искусства по 34 образовательным программам 6 . БГСХА, созданный в 1931 г. как Агропедагогический институт, является центром интеграции

\footnotetext{
${ }^{4}$ Образовательные программы БГУ.URL: http://www.bsu.ru/education/programs/

${ }^{5}$ Образовательные программы ВСГУТУ. URL: https:/esstu.ru/uportal/sveden/education

${ }^{6}$ Вуз сегодня. URL: http://www.vsgaki.ru/about-the-institute/basic-information/universitytoday/
} 
аграрного образования, науки и производства Восточной Сибири. Обучение осуществляется по 40 программам образования ${ }^{7}$.

Согласно Мониторингу эффективности деятельности организаций высшего образования, проведенного Министерством образования и науки РФ в 2017 г., ${ }^{8}$ ни один из республиканских вузов не достиг пороговых значений по восьми основным показателям. Так, значение показателя эффективности трудоустройства ниже порогового во всех вузах. Более того, произошло его снижение по сравнению с предыдущим годом. Наименьшее значение наблюдается в БГСХА, что обусловлено главным образом стагнацией сельского хозяйства республики. Именно в этой отрасли с 1990 г. произошло наибольшее сокращение численности занятых $(-52,3 \%)$, которое продолжается по сей день. Показателя эффективности образовательной деятельности достиг только ВСГИК. Наименьшее значение - у БГСХА. При этом сельхозакадемия - единственное в Бурятии учреждение высшего образования, которое по уровню заработной платы профессорско-преподавательского состава достигло порогового значения. Наименьшая зарплата - во ВСГИК. Наиболее благоприятно, по оценке Министерства и образования РФ, в вузах республики развивается международная деятельность и научноисследовательская работа.

\section{Региональные проблемы}

Несмотря на провозглашенную специализацию, в вузах республики происходит дублирование специальностей. В каждом из них львиную долю выпускников составляют специалисты экономической направленности. И хотя в последнее время темпы их выпуска снизились, объемы подготовки по специальности «экономика и управление»-по-прежнему самые высокие на протяжении всего реформенного периода. Это вполне соответствует общероссийским тенденциям. Доля экономистов и управленцев в структуре выпуска 2016 г. составила $29,1 \%{ }^{9}$, юристов $-8,9 \%$.

${ }^{7}$ Абитуриенту: Направления подготовки / Образовательные программы. URL: http://www.bgsha.ru/abitur/bachelor/\#main_abiturНаправленность аспирантуры. URL: http://www.bgsha.ru/aspirantura-i-doktorantura/spetsialnosti.html

${ }^{8}$ Республика Бурятия. URL: http://indicators.miccedu.ru/monitoring/_vpo/material. php?type $=2 \&$ id $=11004$

${ }^{9}$ Статистический ежегодник: стат. сб. / Бурятстат. 2017. С. 178-179. 
Доля каждой из остальных специальностей в общем числе выпускников не превышает $6 \%$. На начальных этапах реформ структура подготовки кадров была более сбалансированной.

Задержки с выбором ректора в ВСГИК и БГСХА негативно сказываются на эффективности этих вузов. В первом случае это утрата в 2014 г. статуса академии, присвоенного в 1995 г. Во втором - лишение в 2016 г. экономических специальностей государственной аккредитации. Здесь следует отметить, что такая ситуация характерна для многих сельскохозяйственных вузов, которые испытывают трудности в получении аккредитации по непрофильным специальностям. Так, Новосибирский государственный аграрный университет в 2018 г. был лишен аккредитации по четырем направлениям подготовки ${ }^{10}$.

Во многом на сложившуюся ситуацию влияет отсутствие координации деятельности региональных вузов ввиду их разной ведомственной принадлежности. БГУ и ВСГУТУ подотчетны Министерству образования и науки РФ, ВСГИК находится в ведении Министерства культуры РФ, а БГСХА - Министерства сельского хозяйства РФ.

Перепроизводство специалистов в сфере экономики и управления и вообще массовизация высшего образования выливаются в нарастание институционального конфликта между системой образования и рынком труда. В регионе отмечены избыток специалистов высшего уровня подготовки и дефицит квалифицированных рабочих. Объемы и перечень специальностей, по которым готовят студентов, не отражают происшедших изменений на рынке труда. На уровне региона нет единой рыночной образовательной политики Как следствие, часть выпускников остаются невостребованными на рынке (рис. 2).

Таким образом, с одной стороны, развитие высшего образования имеет ряд положительных следствий-удовлетворение спроса в овладении компетенциями при переходе к новому обществу, демократизации и доступности образовательных услуг, снижение риска безработицы и усиление конкурентных преимуществ работников.

\footnotetext{
${ }^{10}$ Уведомление о лишении государственной аккредитации по отдельным направлениям подготовки. URL: https://nsau.edu.ru/news/54711.html
} 
Выпуск, 2016 г.

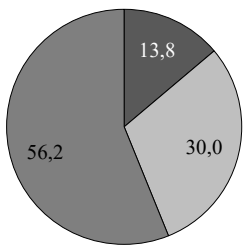

$\square$ СПО (Квалифицированные рабочие) $\square$ СПО (Специалисты)

घВПО
Структура вакансий, 2016 г.

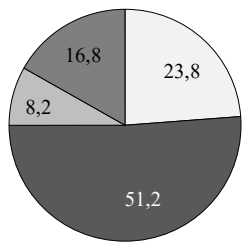

口Без ПО

口СпО (Квалифицированные рабочие) (

घВПО
Уровень образования занятых 2016 г.

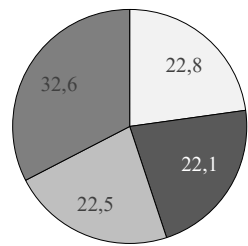

口Без ПО

口СПО (Квалифицированные рабочие) 口СПО (Специалисты)

घВПО

Puc 2. Структура выпуска кадров, вакансий и занятых по уровню образования, 2016 г.,\%

С другой стороны, большинство вакантных рабочих мест не требует высокой квалификации, поэтому некоторым специалистам с высшим образованием придется занимать места, предназначенные для работников с более низкой подготовкой. Разрастание вузов на фоне сокращения бюджетного финансирования ведет к увеличению доли платного образования и, следовательно, его коммерциализации. Это стимулирует вузы в первую очередь к получению прибыли, нередко за счет снижения академических стандартов. Для многих студентов целью обучения становятся не знания, а получение «корочек».

В совокупности это ведет к растущему обесцениванию вузовских дипломов и высшего образования, снижению качества человеческого капитала в целом и структурной безработице, что особенно ярко проявляется в таком регионе, как Республика Бурятия.

\section{Проблема качества образования}

С 2007 г. все потенциальные абитуриенты республики имеют возможность получить высшее образование в вузах региона, что обусловлено снижением численности выпускников общеобразовательных школ, начавшееся после 2004 г., и увеличением числа приема (см. рис. 1). Однако с 2010 по 2016 гг. наблюдается резкий спад приема $(-40 \%)$ и выпуска $(-28 \%)$, в то время как снижение 
выпуска общеобразовательными школами не столь интенсивно $(-19 \%)$. Данная тенденция в определенной мере свидетельствует о падении качества регионального высшего образования.

С введением новых правил приема по результатам ЕГЭ абитуриенты получили широкие возможности при выборе вуза, одним из факторов конкурентоспособности которых становится качество подготовки специалистов. Результаты исследования образовательных стратегий учащихся выпускных классов указывают на высокую значимость качества образования при выборе вуза. Поэтому средний уровень подготовленности абитуриентов, поступающих в региональные вузы, а в результате и средний уровень студентов снижается.

Впрочем, опрошенные студенты старших курсов оценили качество получаемого образования в региональных вузах как удовлетворительное. Также основанием для оценки качества образования может служить мнение студентов о правильности сделанного выбора учебного заведения и специальности (рис. 3).

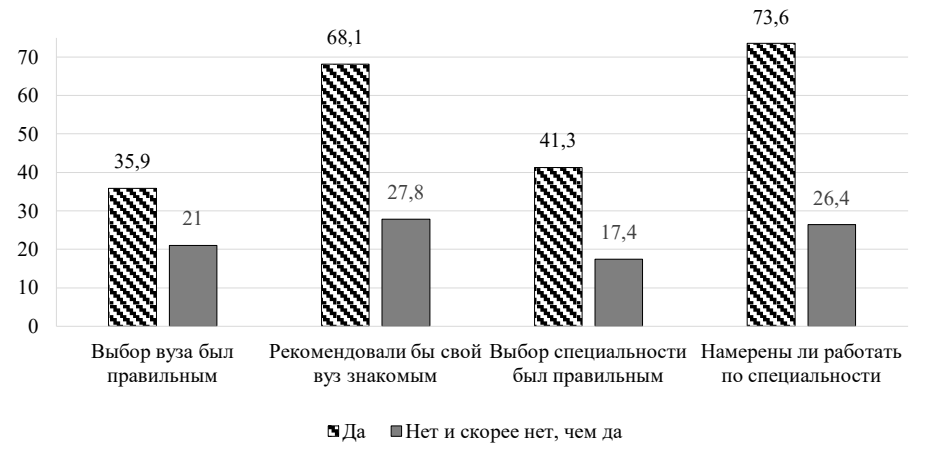

Puc. 3. Оценка образовательного выбора,\% к ответившим

Почти половина опрошенных сомневаются в своем выборе. Более того, каждый пятый указал, что выбрал вуз случайно, а каждый восьмой - специальность. Только для 35,9\% студентов выбор вуза оказался однозначно правильным. С выбором специальности ситуация выглядит немного лучше. В то же время довольно устойчивая мотивация работать по полученной специальности в определенной степени указывает на имеющиеся резервы улучшения качества подготовки, а также на исключение влияния случайных факторов при образовательном выборе. Стоит 
обратить внимание на данный факт и усилить работу по повышению образовательной мотивации студентов. В настоящее время основным стимулом для учебы является желание получить диплом (50\% опрошенных).

Одной из причин снижения качества регионального образования, на наш взгляд, является высокая нагрузка на профессорскопреподавательский состав. С 2010 г. численность преподавателей сократилась на 18\%. Сегодня на одного преподавателя в регионе приходится 16 студентов, что превышает значение целевого индикатора, предусмотренного в государственной программе «Развитие образования» на 2013-2020 гг., ${ }^{11}$ на четыре человека. Уровень заработной платы преподавателей вузов Республики Бурятия традиционно один из самых низких в СФО (ниже только в Алтайском крае) $)^{12}$.

\section{Выводы и предложения}

Для преодоления сложившейся в региональной образовательной системе негативной ситуации необходимы глубокие институциональные преобразования, согласование рынка предлагаемых образовательных услуг с кадровыми потребностями республики, повышение качества профессиональной подготовки и введение в практику системы его оценок на основе регулярного мониторинга качества образования через выявление степени удовлетворенности обучающихся. Это необходимо не только для контроля, но и для проведения аналитических исследований, корректировки образовательных программ, разработки комплекса мер по повышению качества образовательных услуг исходя из потребностей работодателей. Он может стать основой создания и внедрения системы управления качеством образовательной деятельности.

Качество обучения вузов зависит от ресурсов, которыми они располагают, поэтому одним из решений данной проблемы могло бы стать создание опорного вуза в республике на базе БГУ или ВСГУТУ, либо их объединения. Не секрет, что статус

\footnotetext{
${ }^{11}$ Постановление Правительства РФ от 31 марта 2017 г. № 376 «О внесении изменений в государственную программу Российской Федерации "Развитие образования" на 20132020 годы». URL: https://www.garant.ru/products/ipo/prime/doc/71546294/

${ }^{12}$ Итоги федерального статистического наблюдения в сфере оплаты труда отдельных категорий работников социальной сферы и науки за 2017 год. URL: http://www.gks.ru/ free_doc/new_site/population/trud/itog_monitor/itog-monitor4-17.html
} 
опорного предполагает получение дополнительных финансовых, экономических и кадровых ресурсов, необходимых для модернизации вуза, что позволит нивелировать негативные для Бурятии эффекты от создания университетов, ориентированных на федеральное и глобальное лидерство, и развивать высшее образование в республике. Как показывает практика, статус опорного вуза резко повышает внешнюю и внутреннюю активность, меняется городская среда [Чернышов, 2018].

Необходимость такого вуза назрела и по причине того, что на обширной территории Восточной Сибири и Дальнего Востока дальше г. Красноярска нет ни одного опорного вуза. Между тем его создание могло бы выступить фактором привлечения абитуриентов и сдерживания образовательной миграции талантливой молодежи, процент возврата которой ничтожно мал. Миграция выпускников школ с высокими баллами ЕГЭ, помимо проблем с набором в республиканских вузах, потенциально может привести к негативным последствиям для развития региона с точки зрения кадрового обеспечения и формирования региональных элит. Это особо проблемная зона для Сибири и Дальнего Востока. Кроме того, Республика Бурятия является приграничным регионом, и угроза его обезлюживания становится уже общегосударственной проблемой. Создание опорного вуза предполагает его вовлечение в процессы регионального развития, установления более тесных связей с региональными властями, предприятиями, адаптацией оказываемых услуг под запросы рынка труда и местных сообществ.

Сегодня республика не обладает ярко выраженной специализацией в глобальном разделении труда. Между тем она могла бы выступить в качестве пилотного региона по апробации новых механизмов создания и развития современных несырьевых производств [Дондоков, 2018], развитию принципов «зеленой экономики», так как большая часть территории республики входит в Байкальскую природную территорию с особым режимом хозяйственной деятельности. Соответственно в задачи создания опорного вуза должно входить предоставление уникальных возможностей для обучающихся в сфере экологии и охраны окружающей среды, рационального использования природных ресурсов. Предпосылки развития данного направления подготовки уже имеются в ВСГУТУ. 
Кроме того, в условиях роста международного сотрудничества со странами Азиатско-Тихоокеанского региона Бурятия становится стратегически важным регионом. Ее приграничное расположение обеспечивает возможность реализации в рамках экономического коридора Китай-Монголия-Россия проектов по развитию транзитного транспорта, расширению сотрудничества в промышленном, энергетическом, туристическом, образовательном и научно-техническом секторах. В обозначенных отраслях востребованным станут специалисты со знанием восточных языков, основ ведения бизнеса с указанными странами и т.п. Основой подготовки таких специалистов может стать Восточный институт БГУ.

Пока же в Республике Бурятия система высшего профессионального образования как поставщик квалифицированных кадров не может рассматриваться в качестве основы формирования экономики знаний.

\section{Литература}

Аникина Е.А., Иванкина Л. И., Сорокина Ю. С. Кризис высшего образования в России: проявления, причины и последствия // Современные проблемы науки и образования. 2016. № 3. С. 344.

Арсентьева Н. М., Харченко И. И. Формирование кадровой базы современной экономики // Ректор вуза. 2015. № 1. С. 22-29.

Дондоков З. Б.-Д. Стратегические направления социально-экономического развития Бурятии: прошлое, настоящее и лики будущего // Республике Бурятия - 95 лет: сб. науч. ст. Улан-Удэ: Изд-во БНЦ СО РАН, 2018. С. 98-116.

Капелюшников Р.И. Россия: высшее образование обесценивается // Население и общество. 2005. 14 марта. URL: http://polit.ru/article/2005/03/14/ demoscope193 (дата обращения: 15.07.2018)

Кумбс Ф.Г. Кризис образования в современном мире: системный анализ. М.: Прогресс, 1970. 263 с.

Фрумин И., Карной М. и др. Массовое высшее образование. Триумф БРИК? М.: Изд. дом Высшей школы экономики, 2014. 528 с.

Харченко И.И., Бусысин В.П. Система высшего образования и вызовы модернизации // Экономическое развитие России: региональный и отраслевой аспекты / Вып. 8. Новосибирск: ИЭОПП СО РАН, 2007. С. 19-63.

Чернышов $C$. Надежда на опору: история создания опорных университетов в Сибири в четырех частях с антрактом // Новости Сибирской науки. 2018. 29 янв. URL: http://www.sib-science.info/ru/heis/nadezhda-na-oporu-29012018 (дата обращения: 26.07.2018) 


\section{Summary}

Byuraeva Yu.G., Leading Researcher, Department of Regional Economic Studies of the Buryat Science Center, SB RAS, Ulan-Ude

\section{The Institutional Changes in the System of the Higher Education in the Republic of Buryatia}

The modern trends in the system of higher education of the Republic of Buryatia concerning the consequences of its massification are analyzed in the article. The author focuses on the crisis moments, the unpreparedness of higher education in peripheral regions to become the basis for the formation of the knowledge economy due to the decline in the quality of education, qualitative and quantitative discrepancy of the graduates to the real needs of the regional economy by the profile and level of education. It is necessary to find own ways to develop the higher education in the region by providing unique opportunities for students. The main conclusions are based on the author's sociological researches on the education quality and the labour market in the Republic of Buryatia. quality

Higher education; Republic of Buryatia; region; education reform; education

\section{References}

Anikina E.A., Ivankina L. I., Sorokina Yu.S. (2016) Krizis vy`sshego obrazovaniya v Rossii: proyavleniya, prichiny` i posledstviya, Sovremenny 'e problemy`nauki i obrazovaniya [Modern Problems of Science and Education], No. 3. Pp. 344. (In Russ.)

Arsent eva N.M., Xarchenko I.I. (2015) Formirovanie kadrovoj bazy` sovremennoj e'konomiki, Rektor vuza [Rector of the University], No 1. Pp. 22-29. (In Russ.)

Dondokov Z. B.-D. (2018) Strategicheskie napravleniya social'noe'konomicheskogo razvitiya Buryatii: proshloe, nastoyashhee i liki budushhego, In: Respublike Buryatiya - 95 let. Sbornik statej, Ulan-Ude, BNTS SO RAN Publ. Pp. 98-116. (In Russ.)

Kapelyushnikov R.I. (2005) Rossiya: vysshee obrazovanie obescenivaetsya, Naselenie $i$ obshchestvo [Population and Society]. Availabl at: http://polit.ru/ article/2005/03/14/demoscope193 (accessed 15.07.2018). (In Russ.)

Kumbs F. G. (1970) Krizis obrazovaniya v sovremennom mire: sistemny`j analiz. Monografiya, Moscow, Progress Publ. 229 p. (In Russ.)

Frumin I., Karnoj M. i dr. (2014) Massovoe vy`sshee obrazovanie. Triumf BRIK? Monografiya, Moscow, Izd. dom Vy`sshej shkoly` e`konomiki Publ. 528 p. (In Russ.)

Xarchenko I.I., Busy`gin V.P. (2007) Sistema vy`sshego obrazovaniya i vy`zovy` modernizacii, In: E`konomicheskoe razvitie Rossii: regional`ny ’ j i otraslevoj aspekty. Novosibirsk, IEOPP SO RAN Publ. Vol. 8. Pp. 19-63. (In Russ.)

Cherny`shov S. (2018) Nadezhda na oporu: istoriya sozdaniya oporny`x universitetov v Sibiri v chety`rex chastyax s antrakto, Novosti Sibirskoj nauki [News of the Siberian Science]. Availabl at: http://www.sib-science.info/ru/heis/nadezhdana-oporu-29012018 (accessed 26.07.2018) (In Russ.) 